\title{
Effects of Long-term Acetyl-L-carnitine Administration in Rats: I. Increased Dopamine Output in Mesocorticolimbic Areas and Protection toward Acute Stress Exposure
}

Pierluigi Tolu, Ph.D., Flavio Masi, Ph.D., Benedetta Leggio, Ph.D., Simona Scheggi, Ph.D., Alessandro Tagliamonte, Ph.D., M. Graziella De Montis, Ph.D., and Carla Gambarana, M.D.

Acetyl-L-carnitine (ALCAR) is the acetyl ester of carnitine that has been reported to be beneficial in depressive disorders and Alzheimer's disease. A 7-day administration of ALCAR in rats increased dopamine and serotonin output in the nucleus accumbens shell and it prevented the development of escape deficit produced by acute exposure to unavoidable stress. No tolerance developed to this protective effect, which appeared to be mediated by (1) the activation of $5-H T_{1 A}$ receptors, as it was antagonized by the administration of WAY100635 30 min before stress exposure; and (2) a process of neuronal plasticity dependent on NMDA receptor activity, as subcutaneous dizocilpine infusion during ALCAR treatment prevented the development of the protective effect on stress. Chronic stress exposure maintains an escape deficit condition that is reverted by a long-term treatment with antidepressants, but the same condition was not modified by long-term ALCAR administration. Thus, ALCAR cannot be defined as an antidepressant.

[Neuropsychopharmacology 27:410-420, 2002] (C) 2002 American College of Neuropsychopharmacology. Published by Elsevier Science Inc.
KEY WORDS: Acetyl-L-carnitine; Dopamine; Escape deficit; Nucleus accumbens shell; Serotonin; Stress

Acetyl-L-carnitine (ALCAR) is the acetyl ester of carnitine and both carnitine and ALCAR play an essential regulatory role in fatty acid oxidation (Fritz 1963; Bieber 1988). ALCAR has a modulating influence on the structure, function and metabolism of cell membranes

From the Department of Neuroscience, Pharmacology Unit, University of Siena, Siena, Italy (PT, FM, BL, SS, AT, CG), and Department of Scienze del Farmaco, University of Sassari, Sassari, Italy (MGDM).

Address correspondence to: Carla Gambarana, Department of Neuroscience Pharmacology Unit, Via Aldo Moro, 4, 53100 Siena, Italy. Tel.:-39-0577-234116; Fax: -39-0577-234208; E-mail: gambarana@ unisi.it

Received May 9, 2001; revised January 28, 2002; accepted February $8,2002$.

Online publication: 2/11/02 at www.acnp.org/citations/ Npp021102242.
(Villa et al. 1988; Aureli et al. 1990; Arduini et al. 1993; Butterfield and Rangachari 1993), and on energy metabolism (Aureli et al. 1990; Rosenthal et al. 1992; Blokland et al. 1993; Liu et al. 1993; Prickaerts et al. 1995; Rao et al. 1997). There is increasing evidence that abnormalities in fatty acid and membrane phospholipid metabolism play a part in a wide range of neurodevelopmental and psychiatric disorders (Richardson and Ross 2000; Bell et al. 2000; Richardson and Puri 2000). ALCAR also inhibits apoptosis (Galli and Fratelli 1993), activates protein kinase C (Pascale et al. 1994), exerts anti-amnesic activity (Pascale et al. 1994), and improves performance in spatial learning tasks in aged rats (Ghirardi et al. 1988). In controlled studies, ALCAR has been reported to have beneficial effects in major depressive disorders and Alzheimer's disease, both of which are highly prevalent in the geriatric population (Bella et al. 1990; Garzya et al. 1990; Pettegrew et al. 1995, 2000). How- 
ever, the reported antidepressant activity of ALCAR in the elderly might not necessarily be explained in terms of altered fatty acid membrane composition. The data regarding endogenous ALCAR distribution in rat brain, as well as those on the entry of ALCAR through the blood brain barrier, offer an unsatisfactory rationale for the reported pharmacological effects. Total carnitine in different brain areas appears to be homogeneously distributed, and its concentration is about 2.5 times higher in the hypothalamus than in the other areas. ALCAR is present at 25-35\%, long chain acyl-carnitine at $10-15 \%$, and free carnitine at $45-60 \%$ (Bresolin et al. 1982). Only a very small amount of $\left[{ }^{3} \mathrm{H}\right]$-acetyl-carnitine was found in the brain after a pulse i.v. injection with a tracer dose (Farrel et al. 1986). Furthermore, a PET study in primates and humans on the brain localization of ALCAR, labeled with $\left[{ }^{11} \mathrm{C}\right]$ in different positions and pulse injected i.v., came to the likely conclusion that only the acetic acid moiety enters the brain (Kuratsune et al. 1997). A study of Alzheimer patients, treated for 10 days with ALCAR by i.v. infusion and for a further 50 days by oral administration $(2000 \mathrm{mg} /$ day divided into three daily doses), showed a significant increase in the CSF concentration of acetyl-L-carnitine at days 10 and 60 of treatment compared with basal values (Parnetti et al. 1997).

Data presented in the literature suggest that ALCAR may prevent some of the neurochemical sequelae of stress exposure. In fact, repeated ALCAR treatments prevent a stress induced decrease in nerve growth factor binding in rat brain (Foreman et al. 1995), and ALCAR counteracts the increase in $\beta$-endorphine induced by repeated exposure to stress (Bidzinska et al. 1993). Moreover, ALCAR seems to improve the feedback control of hypothalamus-pituitary-adrenal axis response to stress, at least in aged rats (Angelucci and Ramacci 1989; Patacchioli et al. 1989). Thus, in the present study we investigated the effect of ALCAR in a series of behavioral paradigms induced by exposure to unavoidable stress that consistently respond to classical antidepressants (Gambarana et al. 1995a, 2001; Ghiglieri et al. 1997). The first model (acute escape deficit) consists of a decreased response to aversive stimuli and is a modified version of the learned helplessness paradigm. It allows us to evaluate the activity of a treatment in preventing the development of behavioral sequelae following unavoidable stress exposure. The second paradigm is a condition of chronic escape deficit, which begins as acute escape deficit and then can be indefinitely sustained by the repeated administration of mild stressors. This model allows us to evaluate the capacity of a treatment to revert the condition of escape deficit. Moreover, we have measured the effect of repeated ALCAR administration on the extraneuronal concentration of dopamine (DA) and serotonin (5-HT), both in basal conditions and after inhibition of the monoamine trans- porters with cocaine, in the nucleus accumbens shell (NAcS) and medial prefrontal cortex (mPFC). The aims of our study were to assess a possible antidepressant activity of ALCAR in animal models, and to investigate whether such activity may be related to a change in the transmission of one or more monoamines in the frontomesolimbic system.

\section{METHODS}

\section{Animals}

Experiments were carried out on male Sprague-Dawley rats (Charles River, Calco, Italy) weighing 125-150 g at their arrival in the vivarium. Animals were housed 5 per cage $(59 \times 38.5 \times 20 \mathrm{~cm})$ for the entire duration of the experiments and they were moved to a different cage or apparatus only for the time required for the behavioral manipulation. They were kept in an environment maintained at a constant temperature and humidity, with free access to food and water. A $12 \mathrm{~h}$ inverted light/dark cycle (lights off at 7:00 A.M.) was used. Experiments were carried out from 9:00 A.M. to 5:00 P.M. under a red light and controlled noise conditions in a testing room separated from and adjacent to the main animal room, under the same conditions of temperature and humidity. Rats were allowed at least one week of habituation to the animal colony; when experimental procedures began they weighed $200-225 \mathrm{~g}$.

The procedures used in this study are in strict accordance with the European legislation on the use and care of laboratory animals (EEC n. 86/609), with the guidelines of the National Institutes of Health on the use and care of laboratory animals, and had the approval of the local Ethical Committee.

\section{Antinociceptive Test}

Pain threshold was assessed by the radiant heat tail-flick method according to D'Amour and Smith (1941). The animals were taken into the test room, placed on the tailflick apparatus (Ugo Basile, Italy), and the radiant heat intensity was adjusted to obtain average latency values of $5 \mathrm{~s}$ in control animals. A $10 \mathrm{~s}$ cut-off point was employed to prevent tissue damage to the tail.

\section{Locomotor Activity}

Rats were individually placed in locomotor activity cages (M/P40 Fc Electronic Motility Meter, Motor Products, Stockholm). Each cage had 40 photo-conductive sensors in the floor area $(21 \times 32 \mathrm{~cm})$ at a fixed distance of $4 \mathrm{~cm}$. These sensors and the arena were uniformly illuminated by an incandescent lamp mounted $60 \mathrm{~cm}$ above the floor. Motor activity was defined as the number of interruptions of a beam during a 30-min observa- 
tion period. Five days before the test, animals were placed in the motility cage for $15 \mathrm{~min} /$ day. On test day, rats were observed for $30 \mathrm{~min}$ after a 10-min habituation period.

\section{Acute Escape Deficit}

Apparatus. A dark Plexiglas cage $(30 \times 60 \times 30 \mathrm{~cm})$ with a floor fitted with stainless steel rods spaced $1 \mathrm{~cm}$ apart was divided into two equal chambers by a dark partition with a $10 \times 10 \mathrm{~cm}$ sliding door. One compartment was connected to a S48 Grass stimulator (Grass Instrument, Astro-Med Inc., West Warwick, RI, USA) (electrified chamber), while the other was disconnected from it (neutral chamber).

Procedure. The experimental procedure, previously described in detail (Gambarana et al. 2001), consisted in the exposure to unavoidable stress (pre-test) followed by an escape test. Briefly, rats were immobilized with a flexible wire-net, an electrode was applied to the distal third of the tail, and about 80 electric shocks $(1 \mathrm{~mA} \times 5$ s, 1 every $30 \mathrm{~s}$ ) were administered; $24 \mathrm{~h}$ later, rats were tested in a shock-escape paradigm in the Plexiglas cage. The number of escapes out of 30 trials was recorded.

\section{Chronic Escape Deficit}

For the chronic stress procedure, rats were initially exposed to the sequence of pre-test and escape test trials described above. Then, rats selected on the basis of their failure to escape ( $0-3$ escapes/ 30 trials), were subjected to the following procedure, starting $48 \mathrm{~h}$ after the escape test: (1) were restrained for $10 \mathrm{~min}$; (2) received $10 \mathrm{~min}$ of restraint plus four unavoidable shocks, $48 \mathrm{~h}$ after (1); (3) spent $20 \mathrm{~min}$ in the cage where the unavoidable shock had previously been administered, $48 \mathrm{~h}$ after (2). By repeating this procedure on alternate days, the escape deficit can be maintained in all rats (De Montis et al. 1995).

\section{Microdialysis Procedure}

Anesthetized rats (pentobarbital $50 \mathrm{mg} / \mathrm{kg}$, scopolamine $0.4 \mathrm{mg} / \mathrm{kg}$, i.p.) were placed in a stereotaxic instrument and two concentric vertical probes were lowered into the NAcS (AP $+1.7 \mathrm{~mm}, \mathrm{~L} \pm 1.2 \mathrm{~mm}, \mathrm{~V}-8.0$ $\mathrm{mm})$ and the $\mathrm{mPFC}(\mathrm{AP}+3.7 \mathrm{~mm}, \mathrm{~L} \pm 0.7 \mathrm{~mm}, \mathrm{~V}-5.0$ $\mathrm{mm}$ ), according to Paxinos and Watson (1986). Concentric microdialysis probes were made from semipermeable dialysis tubing (ID: $0.22 \mathrm{~mm}$; OD: $0.31 \mathrm{~mm}$; AN 69, Hospal, Bologna, Italy). The length of the permeable portion of the membrane was $2.0 \mathrm{~mm}$ for the NAcS, and $3.0 \mathrm{~mm}$ for the $\mathrm{mPFC}$. The probes were fixed to the skull with stainless steel screws and dental cement, and the skin was sutured. After surgery, the animals were housed individually in a microdialysis Plexiglas box $(20 \times$ $30 \times 30 \mathrm{~cm}$ ) with a grid floor and an open top, and $24 \mathrm{~h}$ of recovery and habituation to the chamber were allowed before the beginning of microdialysis. On the day of the experiment, a solution of artificial cerebrospinal fluid (147 mM NaCl, $2.2 \mathrm{mM} \mathrm{CaCl} 2,4 \mathrm{mM}$ $\mathrm{KCl}$ ) was infused at a flow rate of $1 \mu \mathrm{l} / \mathrm{min}$ through the probe. After a $2 \mathrm{~h}$ equilibration period, dialysate samples were collected every $15 \mathrm{~min}$ (NAcS) or every 25 min (mPFC). At least 4-5 samples were obtained for the estimation of basal levels. Then, the animals received a cocaine injection ( $5 \mathrm{mg} / \mathrm{kg}$ i.p.) and four samples were collected.

Dialysate samples were immediately analyzed by reverse-phase High Performance Liquid Chromatography (HPLC) with electrochemical detection. Monoamines were eluted on a C-18 reverse phase column (Supelco LC18 DB). The detector was an ESA Coulochem II with a 5014 A microdialysis cell. The potential of the first electrode was set at $+175 \mathrm{mV}$, and that of the second electrode at $-175 \mathrm{mV}$. The mobile phase consisted of an aqueous solution containing: $33 \mathrm{mM}$ $\mathrm{NaH}_{2} \mathrm{PO}_{4}, 0.1 \mathrm{mM} \mathrm{Na} 2 \mathrm{EDTA}, 1 \mathrm{mM}$ sodium dodecyl sulfate, $20 \%$ methanol (vol/vol) and $15 \%$ acetonitrile ( $\mathrm{vol} / \mathrm{vol}$ ), $\mathrm{pH}$ 5.7. A flow-rate of $1.0 \mathrm{ml} / \mathrm{min}$ was used. Data were taken by PC using EZChrom 6.6 software (Scientific Software Inc., San Ramon, CA, U.S.A.) and quantified based on peak area by comparison with a standard curve run before and after each experiment.

At the end of the experiment, rats were killed to verify the positioning of the probes. Microdialysis data was utilized only when the correct positioning of the probes had been microscopically confirmed on cresyl violet-stained brain sections.

\section{Drugs}

ALCAR, SCH 23390, d,l-propranolol, WAY100135 and cocaine were dissolved in $0.9 \%$ saline and injected in a volume of $1 \mathrm{ml} / \mathrm{kg}$ rat body weight. Dizocilpine was dissolved in $0.9 \%$ saline and released by s. c. implanted osmotic minipumps (ALZET ${ }^{\circledR}$ pumps, Palo Alto, CA). Pentobarbital was dissolved in a mixture of $12 \%$ ethanol, $38 \%$ propylene glycol, $50 \%$ deionized/distilled water (vol/ vol) and was injected in a volume of $4 \mathrm{ml} / \mathrm{kg}$ rat body weight. Scopolamine was dissolved in deionized/distilled water. All chemicals were purchased from commercial sources; cocaine was purchased from SALARS (Como, Italy). ALCAR was donated by Sigma-Tau (Pomezia, Italy).

\section{Statistical Analysis}

Statistical analyses were performed on commercially available software (Instat 2.01 for Macintosh, GraphPad software Inc., San Diego, CA, USA). All data are expressed as mean \pm S.E.M. Comparisons were made by $t$-test when two experimental groups were compared. Otherwise, comparisons were made by 1-way analysis of 
variance (ANOVA), followed by post-hoc Bonferroni's or Dunnett's test, when applicable $(p<.05)$. When the criteria for parametric statistics were not met by the data, non-parametric analysis of variance (Kruskal-Wallis test) was used; when differences between groups were significant $(p<.05)$, the data were subjected to post-hoc analysis using Dunn's test, a variation of Bonferroni's test for non-parametric ANOVA.

\section{RESULTS}

\section{Effect of a Single Administration of ALCAR on Acute Escape Deficit}

The effect of a single treatment with different doses of ALCAR on the development of acute escape deficit by rats was initially examined. Fifty rats were divided into five groups of 10 animals each that received $3,6,10$, or $20 \mathrm{mg} / \mathrm{kg}$ of ALCAR or saline $(1 \mathrm{ml} / \mathrm{kg})$ i.p. $60 \mathrm{~min}$ before the inescapable shock session, respectively, and that were tested for escape $24 \mathrm{~h}$ later. A sixth group of 10 saline treated rats was only tested for escape (Naive). ALCAR treated rats performed in the same way as control rats (Table 1). Analysis of the data by ANOVA test demonstrated a significant difference between groups $\left(\mathrm{F}_{54,59}=232.20, p<.001\right)$; post-hoc Bonferroni's test showed that only the score of Naive rats was significantly different from the score of control and ALCAR treated rats $(p<.001$, for all comparisons).

\section{Effect of a 7-day ALCAR Treatment on Acute Escape Deficit}

Rats received 3, 6, or $10 \mathrm{mg} / \mathrm{kg}$ of ALCAR or saline (1 $\mathrm{ml} / \mathrm{kg}$ ) twice a day, i.p. for seven days $(\mathrm{n}=10$ for each

Table 1. Effect of a Single or Repeated Treatment with ALCAR on the Development of Acute ED

\begin{tabular}{lcc}
\hline & \multicolumn{2}{c}{ Number of escapes } \\
\cline { 2 - 3 } Group & $\begin{array}{c}\text { Single } \\
\text { administration }\end{array}$ & $\begin{array}{c}\text { 7-day } \\
\text { administration }\end{array}$ \\
\hline Naive & $23.9 \pm 0.9$ & $23.0 \pm 1.0$ \\
Ctr & $1.4 \pm 0.5^{* * *}$ & $1.0 \pm 0.5^{* *}$ \\
$A L C A R 3 \mathrm{mg} / \mathrm{kg}$ & $1.5 \pm 0.5^{* * *}$ & $3.2 \pm 1.0^{* *}$ \\
$A L C A R 6 \mathrm{mg} / \mathrm{kg}$ & $2.1 \pm 0.5^{* * *}$ & $2.7 \pm 0.8^{* *}$ \\
$A L C A R 10 \mathrm{mg} / \mathrm{kg}$ & $2.2 \pm 0.6^{* * *}$ & $20.3 \pm 1.6$ \\
$A L C A R 20 \mathrm{mg} / \mathrm{kg}$ & $1.9 \pm 0.5^{* * *}$ & - \\
\hline
\end{tabular}

ALCAR was administered i.p. 60 min before the exposure to unavoidable stress (single administration) or it was administered twice a day for 7 days before the sequence of pre-test and escape test. Naive and Ctr groups received saline acutely or for 7 days. Data are expressed as mean \pm S.E.M. of the number of escapes out of 30 trials.

${ }_{* * *} p<.001$ vs. the score of Naive group (ANOVA with Dunnett multiple comparisons test).

${ }_{* *} p<.01$ vs. the score of the Naive and ALCAR $10 \mathrm{mg} / \mathrm{kg}$ groups (ANOVA with Dunnett multiple comparisons test). group); 18-20 h after the last treatment they were exposed to the pre-test and $24 \mathrm{~h}$ later to the escape test. A group of saline treated rats $(n=10)$ was only tested for escape (Naive). Analysis of the data by ANOVA showed a significant difference between groups $\left(\mathrm{F}_{25,29}=\right.$ 103.61, $p<.001)$. Bonferroni's test demonstrated that rats treated for seven days with ALCAR $10 \mathrm{mg} / \mathrm{kg}$ twice a day had a significantly higher number of escapes than rats in the control group and rats treated with ALCAR 3 or $6 \mathrm{mg} / \mathrm{kg}$ twice a day $(p<.001$, for all three comparisons) (Table 1).

\section{Effect of a 7-day ALCAR Treatment on Monoaminergic Transmission}

Rats received saline $(1 \mathrm{ml} / \mathrm{kg}, \mathrm{n}=10$, Control $)$ or ALCAR $(10 \mathrm{mg} / \mathrm{kg}, \mathrm{n}=10, A L C A R)$ i.p. twice a day for seven days; on day 8 they were implanted with microdialysis probes in the NAcS and MPFC, and on day 9 they underwent microdialysis. In the NAcS, basal levels of extraneuronal DA and 5-HT were higher in the $A L-$ CAR group than in the $C t r$ group $(p<.01$ and $p<.05$, respectively, unpaired $t$-test) (Figure 1, panels $A$ and $B$ ). Then, when baseline levels had been determined, the animals received an injection of cocaine $(5 \mathrm{mg} / \mathrm{kg}$ i.p.) and four samples were collected. Because of the significant difference in the basal levels of extraneuronal monoamines between the groups, variations in levels after acute uptake inhibition were not calculated as percentage increases compared with basal values. DA and 5-HT accumulation was calculated as the sum of the absolute amounts of the monoamine (measured values minus the mean basal value) in each of the four samples collected following cocaine administration. The output of DA and 5-HT in the ALCAR group was significantly higher than in the Ctr group $(p<.001$ and $p<.01$, respectively, unpaired $t$-test) (Figure 1, panels $C$ and $D$ ).

In the $\mathrm{mPFC}$, no significant differences were observed between groups in the basal values and in the accumulation after uptake inhibition of DA and 5-HT (data not shown).

\section{Lack of Tolerance to the Protective Effect of ALCAR}

In order to establish whether tolerance might develop to the protective effect of ALCAR on acute stress, rats were exposed to the sequence of pre-test and test after $5,10,20$, or 40 days of ALCAR treatment $(10 \mathrm{mg} / \mathrm{kg}$, i.p. twice a day) ( $\mathrm{n}=10$ for each group). Analysis of the data by ANOVA showed a significant difference between group performances $\left(\mathrm{F}_{54,59}=132.36, p<.001\right)$. Dunnett's test indicated that no tolerance developed to the effect of ALCAR after a long-term treatment, as there was a significant difference between the number of escapes of the Ctr group and the Naive and ALCAR groups (Table 2). 


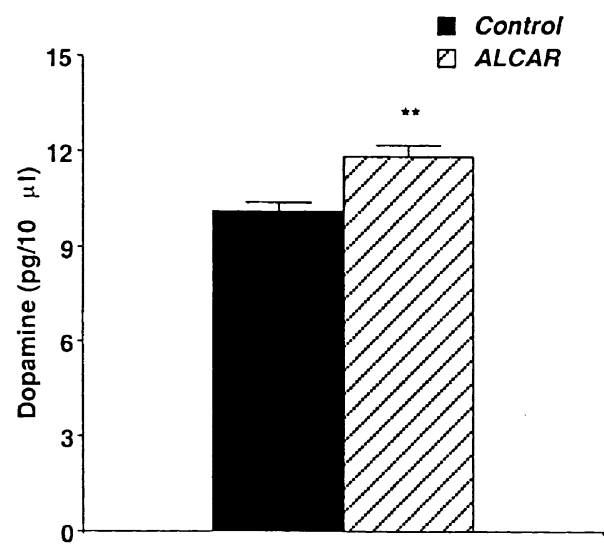

A

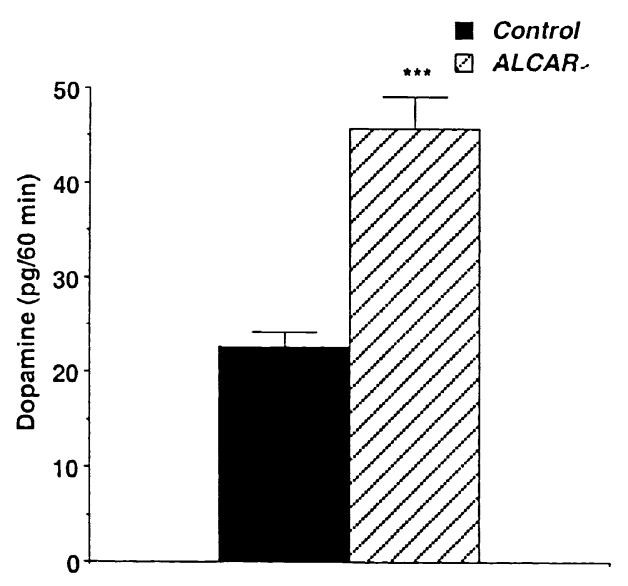

C

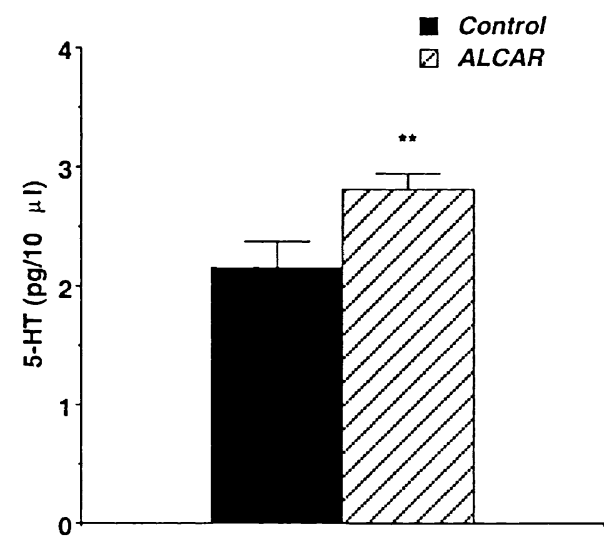

B

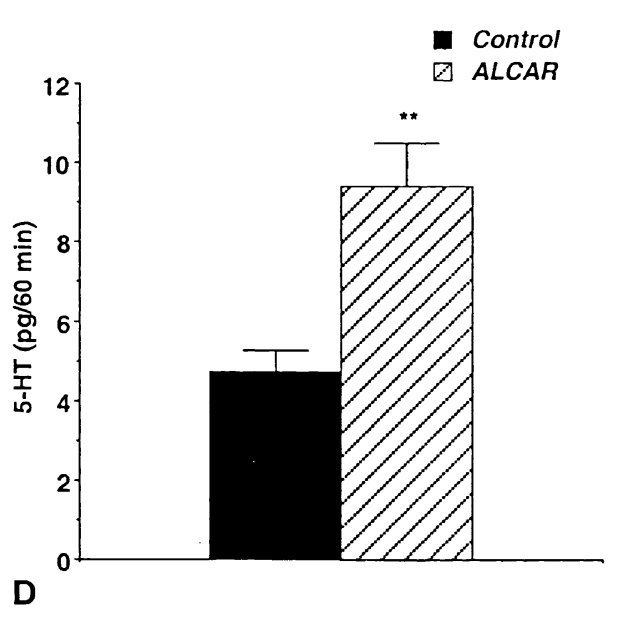

Figure 1. Dopamine and serotonin basal levels (A and B) and accumulation (C and D) in the NAcS after a 7-day ALCAR treatment. Rats received saline (Control) or ALCAR (ALCAR) for seven days, they underwent surgery on day 8 , and then microdialysis experiments were performed $48 \mathrm{~h}$ after the last treatment. (Control, $\mathrm{n}=10$; ALCAR, $\mathrm{n}=10)$. A, B. Dopamine and serotonin basal levels. Values represent the mean of four samples for each rat \pm S.E.M.

** $p<.01$ compared with the extraneuronal levels in the Control group.

C, D. Dopamine and serotonin accumulation after cocaine administration (5 mg/kg, i.p.). Values represent the mean \pm S.E.M. of the sums of four samples collected from each rat after cocaine administration, minus the mean basal level.

*** $p<.001$, compared with the output in the Control group.

** $p<.01$, compared with the output in the Control group.

\section{Effect of Long-term ALCAR on Pain Threshold and Motor Activity}

To exclude a non-specific analgesic effect of repeated ALCAR treatment, which would constitute a major bias in evaluating a reduction of behavioral sequelae to a nociceptive stimulus, two groups of 10 rats each were tested with the radiant heat tail-flick method after seven days of treatment with ALCAR $(10 \mathrm{mg} / \mathrm{kg})$ or saline $(1 \mathrm{ml} / \mathrm{kg})$ i.p., twice a day. In the tail-flick test the ALCAR treated rats did not show any modification in pain threshold compared with the saline treated rats (mean latency value \pm S.E.M. for the $C t r$ group: $4.6 \pm$ $0.1 \mathrm{~s}$, for the ALCAR group: $4.9 \pm 0.2 \mathrm{~s}$ ).

In order to verify whether repeated ALCAR treatment had a stimulant activity, which would constitute a bias in evaluating avoidance (Gambarana et al. 1995b), the two groups of rats were tested for spontaneous locomotor activity after 15 days of treatment, $2 \mathrm{~h}$ after the last drug administration. No differences were observed in spontaneous locomotor activity between the ALCAR and the $C t r$ groups (mean motility counts in $30 \mathrm{~min} \pm$ S.E.M. for the Ctr group: $1786 \pm 132$, for the ALCAR group: $1823 \pm 205$ ).

\section{Pharmacological Characterization of ALCAR Protective Effect on Stress}

Experiment 1. To verify whether the observed protective effect was related to a prominent function of a monoaminergic receptor system, 50 rats were treated with ALCAR (10 mg/ $\mathrm{kg}$, i.p. twice a day) for seven days. Then, $30 \mathrm{~min}$ before the exposure to the pre-test:

Table 2. No Tolerance Developed to the Protective Effect of a Long-term Treatment with ALCAR

\begin{tabular}{lc}
\hline Group & Number of escapes \\
\hline Naive & $25.8 \pm 1.0$ \\
Ctr & $1.1 \pm 0.7^{* *}$ \\
$A L C A R$ 5 days & $25.1 \pm 0.9$ \\
$A L C A R$ 14 days & $24.1 \pm 0.9$ \\
$A L C A R$ 30 days & $25.6 \pm 0.7$ \\
$A L C A R$ 40 days & $23.9 \pm 1.0$ \\
\hline
\end{tabular}

ALCAR was administered at the dose of $10 \mathrm{mg} / \mathrm{kg}$ i.p. twice a day for the time indicated. Data are expressed as mean \pm S.E.M. of the number of escapes out of 30 trials.

${ }^{* *} p<.01$ vs. the score of the Naive group (ANOVA with Dunnett multiple comparisons test). 
10 rats received a $D_{1}$ dopaminergic antagonist, $\mathrm{SCH}$ $23390\left(0.03 \mathrm{mg} / \mathrm{kg}\right.$, i.p.); 10 rats received a $5-\mathrm{HT}_{1 \mathrm{~A}}$ serotonergic antagonist, WAY-100635 $(0.2 \mathrm{mg} / \mathrm{kg}$, s. c.); 10 rats received a $\beta$-adrenergic antagonist, propranolol (5 $\mathrm{mg} / \mathrm{kg}$, i.p.); and 10 rats received a $\mathrm{M}_{1}-\mathrm{M}_{2}$ muscarinic receptor antagonist, scopolamine $(0.1 \mathrm{mg} / \mathrm{kg}$, s. c.); 10 received saline $(1 \mathrm{ml} / \mathrm{kg})$. Ten rats (Controls) were treated with saline $(1 \mathrm{ml} / \mathrm{kg}$ i.p. twice a day) for seven days and on day 8 they were exposed to the pre-test session. Twenty-four hours after the pre-test all rats were tested for escape. Table 3 shows that only the pretreatment with the selective $5-\mathrm{HT}_{1 \mathrm{~A}}$ serotonergic antagonist WAY 100635 significantly inhibited the protective effect of a 7-day ALCAR treatment (Kruskal-Wallis non-parametric ANOVA, $\mathrm{KW}=51.165, p<.001$; Dunn's test: $p<.001$ ).

Experiment 2. In order to establish whether the effect of a repeated ALCAR treatment on the development of the escape deficit was dependent on the activity of the NMDA receptor system, the non-competitive NMDA receptor antagonist dizocilpine was utilized. Thirty rats were implanted with osmotic minipumps, which delivered dizocilpine ( $0.1 \mathrm{mg} / \mathrm{kg} /$ day s. c.) for seven days; during the infusion period 10 rats were injected with ALCAR (10 mg/kg i.p. twice a day) and were then exposed to the sequence of pre-test and escape test (Dizocilpine + ALCAR + Stress). The other 20 animals received saline i.p. twice a day; 10 of them were exposed to the sequence of pre-test and escape test (Dizocilpine + Stress), and 10 to the escape test only (Dizocilpine). Twenty rats received saline $(1 \mathrm{ml} / \mathrm{kg}$ i.p. twice a day) for seven days; 10 of them were exposed to the sequence of pre-test and escape test (Stress), and 10 to the escape test only (Naive). Analysis of the number of escapes by ANOVA showed a significant difference between groups $\left(\mathrm{F}_{54,59}=255.61, p<.001\right)$. Dunnett's test demonstrated a significant lower number of escapes in the Stress, Dizocilpine + Stress, and Dizocilpine + ALCAR

Table 3. Selective Antagonism of ALCAR Effect on Acute ED by WAY100635 Administration

\begin{tabular}{lc}
\hline Treatment & Number of escapes \\
\hline Naive & $26.0 \pm 0.8$ \\
Ctr & $3.0 \pm 1.7^{* * *}$ \\
ALCAR + saline & $25.0 \pm 1.8$ \\
ALCAR + SCH 23390 & $22.4 \pm 1.4$ \\
ALCAR + WAY100635 & $4.3 \pm 1.0^{* * *}$ \\
ALCAR + propranolol & $22.2 \pm 2.0$ \\
ALCAR + scopolamine & $18.6 \pm 3.2$ \\
\hline
\end{tabular}

Antagonists were administered $30 \mathrm{~min}$ before the pre-test as follows: $\mathrm{SCH}-23390=0.03 \mathrm{mg} / \mathrm{kg}$ i.p.; WAY $100635=0.2 \mathrm{mg} / \mathrm{kg}$ s. c.; propranolol $=5 \mathrm{mg} / \mathrm{kg}$ i.p.; scopolamine $=0.1 \mathrm{mg} / \mathrm{kg}$ s. c. Data are expressed as mean \pm S.E.M. of the number of escapes out of 30 trials.

*** $p<.001$ vs. the score of the Naive and ALCAR + saline groups (Kruskal-Wallis with Dunn multiple comparisons test).
+ Stress groups compared with the scores of the Naive, Dizocilpine, and Saline + ALCAR + Stress groups $(p<$ .01 , for the four comparisons) (Table 4 ).

\section{Effect of Long-term ALCAR treatment on the Development of Chronic Escape Deficit}

Experiment 1. Rats were exposed to the chronic stress procedure for three weeks while receiving saline $(1 \mathrm{ml} /$ $\mathrm{kg}$, Stress, $\mathrm{n}=10)$ or ALCAR $(10 \mathrm{mg} / \mathrm{kg}$, Stress $+A L-$ $C A R, \mathrm{n}=10)$ twice a day i.p. Ten rats were injected with saline $(1 \mathrm{ml} / \mathrm{kg})$ i.p. twice a day for three weeks (Naive). The day after the end of the protocol all rats were tested for escape. Analysis of the data by ANOVA showed a significant difference between groups $\left(\mathrm{F}_{27,29}=\right.$ 135.54, $p<.001$ ); Dunnett's test demonstrated that ALCAR treatment did not reinstate a normal avoidance response in rats exposed to stress $(p<.01$ compared with the Naive group) (Table 5).

Experiment 2. The persistence of the protective effect of a 7-day ALCAR treatment during long-term treatment and concomitant stress exposure was tested. Ten rats treated i.p. twice a day for two weeks with saline $(1 \mathrm{ml} / \mathrm{kg})$ and 10 treated with ALCAR $(10 \mathrm{mg} / \mathrm{kg})$ underwent the sequence of pre-test and escape test on days 15 and 16. They were then exposed to the chronic stress procedure for three weeks, while continuing the treatment (Chronic Stress and ALCAR + Chronic Stress). Ten more rats were injected i.p. twice a day for five weeks with saline $(1 \mathrm{ml} / \mathrm{kg})$ (Naive), and 10 with ALCAR $(10 \mathrm{mg} / \mathrm{kg})(A L C A R)$. The day after the end of the protocol all rats were tested for escape. Analysis of the data by ANOVA showed a significant difference between the number of escapes of experimental groups $\left(\mathrm{F}_{26,29}=98.347, p<.001\right)$; post-hoc analysis by Dunnett's test demonstrated scores significantly lower in

Table 4. Continuous Infusion with Dizocilpine Antagonized the Effect of Long-term ALCAR Treatment on Acute ED Development

\begin{tabular}{lc}
\hline Group & Number of escapes \\
\hline Naive & $24.8 \pm 0.9$ \\
Stress & $1.1 \pm 0.4^{* * *}$ \\
Dizocilpine & $23.5 \pm 0.8$ \\
Dizocilpine + Stress & $1.3 \pm 0.5^{* *}$ \\
Saline + ALCAR + Stress & $22.7 \pm 1.0$ \\
Dizocilpine + ALCAR + Stress & $6.7 \pm 0.6^{*}$ \\
\hline
\end{tabular}

Dizocilpine was administered s. c. by osmotic mini-pump at the dose of $0.1 \mathrm{mg} / \mathrm{kg} /$ day for seven days. ALCAR was administered at the dose of $10 \mathrm{mg} / \mathrm{kg}$ i.p. twice a day for seven days. Data are expressed as mean \pm S.E.M. of the number of escapes out of 30 trials.

*** $p<.001$ vs. the score of the Naive group (ANOVA with Bonferroni multiple comparisons test).

** $p<.001$ vs. the score of the Dizocilpine group (ANOVA with Bonferroni multiple comparisons test).

${ }^{*} p<.001$ vs. the score of the Saline + ALCAR + Stress group (ANOVA with Bonferroni multiple comparisons test). 
Table 5. ALCAR Treatment and Chronic Stress Exposure

\begin{tabular}{lc}
\hline Group & Number of escapes \\
\hline Naive & $24.0 \pm 0.9$ \\
Stress & $1.8 \pm 0.6^{* *}$ \\
Stress + ALCAR & $3.5 \pm 1.5^{* *}$ \\
\hline
\end{tabular}

Rats were exposed to the sequence of pre-test and escape test, then they began saline (Stress) or ALCAR treatment $(10 \mathrm{mg} / \mathrm{kg}$ b. i. d., i.p.) (Stress $+A L C A R$ ) and the exposure to the chronic stress protocol. Data are expressed as mean \pm S.E.M. of the number of escapes out of 30 trials.

${ }^{* *} p<.01$ vs. the Naive group (ANOVA with Dunnett multiple comparisons test).

the Stress and ALCAR + Stress groups compared with the scores of the Naive and ALCAR groups (Table 6).

\section{DISCUSSION}

ALCAR administered at the dose of $10 \mathrm{mg} / \mathrm{kg}$ twice a day for seven days protected rats from the behavioral sequelae of an unavoidable stress and no tolerance developed to this effect after 40 days of continuous treatment. A higher dose of ALCAR administered acutely before the pre-test did not prevent escape deficit development. Animals treated for seven days with ALCAR had levels of extraneuronal DA in the NAcS significantly higher than the control group, and the accumulation of the monoamine after uptake inhibition in this area exceeded that of control rats. Moreover, they presented a significant increase in both basal and cocaineinduced accumulation of extraneuronal 5-HT in the NAcS. The acute inhibition of the monoamine transporter produced by cocaine, which does not interfere with monoamine release (Di Chiara and Imperato 1988; Hurd and Ungerstedt 1989), induces an extraneuronal accumulation of the monoamines proportional to the amount taken up by nerve terminals, and it can be used as an indicator of monoaminergic neuronal activity

Table 6. ALCAR Treatment and Chronic Stress Exposure

\begin{tabular}{lc}
\hline Group & Number of escapes \\
\hline Naive & $26.0 \pm 1.0$ \\
Stress & $1.6 \pm 0.6^{* * *}$ \\
ALCAR & $23.3 \pm 1.3$ \\
ALCAR + Stress & $4.0 \pm 1.1^{* *}$
\end{tabular}

Rats were pretreated for 14 days ( $10 \mathrm{mg} / \mathrm{kg}$ b. i. d., i.p.), exposed to the sequence of pre-test and escape test, and then they resumed treatment plus exposure to the chronic stress protocol (ALCAR + Stress) or handling $(A L C A R)$. Data are expressed as mean \pm S.E.M. of the number of escapes out of 30 trials.

${ }^{* * *} p<.001$ vs. the Naive group (ANOVA with Bonferroni multiple comparisons test).

${ }^{* *} p<.001$ vs. the ALCAR group (ANOVA with Bonferroni multiple comparisons test).
(Gambarana et al. 1999a, 1999b). No modification in either DA or 5-HT extraneuronal concentrations were observed in the MPFC.

Rats receiving ALCAR treatment under a continuous dizocilpine infusion did not show protection and scored similarly to the Stress group when tested for escape $24 \mathrm{~h}$ after the pre-test. The dose of dizocilpine used $(0.1 \mathrm{mg} / \mathrm{kg} / 24 \mathrm{~h})$ does not produce apparent behavioral alterations, and it prevents the development of the protective effect of imipramine (Meloni et al. 1993) and fluoxetine (Gambarana, unpublished results) on the behavioral and neurochemical sequelae of inescapable stress. Thus, the protective effect of ALCAR on stress appeared to be mediated by a process of neuronal plasticity dependent on NMDA receptor activity. Rats repeatedly treated with ALCAR had a pain threshold, measured with the tail-flick test, similar to that of control animals. Moreover, their spontaneous motor activity did not differ from that of control animals.

The long-term administration of classical antidepressants, such as imipramine and fluoxetine, produces a protective activity on the development of the behavioral sequelae of unavoidable stress similar to that observed with ALCAR (Gambarana et al. 1995a). This protective effect appears to be related to the functional integrity of a specific type of monoamine receptor. Thus, the acute administration of the selective $D_{1}$ dopaminergic antagonist SCH 23390 before the pre-test selectively antagonizes the protective effect of imipramine, while pindolol antagonizes that of fluoxetine (Gambarana et al. 1995a). In order to assess whether the protective effect of ALCAR was sustained by a specific receptor system, rats treated with ALCAR for seven days were acutely administered different selective monoamine receptor antagonists before the pre-test. The doses of each antagonist used were chosen on the basis of previously published results (Gambarana et al. 1995a, 1999c) or of preliminary experiments (scopolamine). Preliminary behavioral data indicated that scopolamine $(0.05-0.2 \mathrm{mg} / \mathrm{kg})$ did not induce overt behavioral modifications (Masi, unpublished results), while some cognitive impairment has been described in rats after scopolamine administration at the same doses (Kirkby et al. 1996). The protective effect of repeated ALCAR administrations was specifically antagonized by WAY100635, a selective silent antagonist of $5-\mathrm{HT}_{1 \mathrm{~A}}$ receptors (Forster et al. 1995), given $30 \mathrm{~min}$ before the pre-test. This data strongly suggests that $5-\mathrm{HT}_{1 \mathrm{~A}}$ receptor activation plays a relevant role in the mechanism of action of ALCAR.

The involvement of brain monoamines in response to stress has been widely investigated (Bliss et al. 1968; Konstandi et al. 2000) and both 5-HT (Courzon 1971; Petty et al. 1992; Chaouloff 2000) and DA (Pani et al. 2000) are considered to play a crucial role in coping with stressful situations. Dopaminergic neurons in the 
ventral tegmental area are rapidly activated by sudden environmental events, including stressful circumstances (Kaneyuki et al. 1991), and acute exposure to different forms of stress has been reported to increase DA release in the PFC (Sorg and Kalivas 1993; Finlay et al. 1995; Yoshioka et al. 1996) as well as in the NAc (Rouge-Pont et al. 1993; Kalivas and Duffy 1995; Tidey and Miczek 1996). It appears that the PFC exerts an inhibitory influence on subcortical dopaminergic transmission. Accordingly, the NAc dopaminergic response to stress, measured by voltammetry, is dampened by the concurrent activation of dopaminergic terminals in the meso-prefrontal cortex, and this action is mediated, at least in part, by $\mathrm{D}_{1}$ dopaminergic receptor stimulation (Doherty and Gratton 1996). Long-term exposure to different stress procedures impairs an animal's responsiveness to both aversive and pleasurable stimuli (Overmier and Seligman 1967; Papp et al. 1991; Moreau et al. 1992; Gambarana et al. 1995a), and it decreases DA output in mesolimbic areas (Di Chiara et al. 1999; Gambarana et al. 1999a; Mangiavacchi et al. 2001). Moreover, 5-HT output in the mPFC increases in response to acute exposure to unavoidable stress (Petty et al. 1992), although no difference has been observed between helpless and non-helpless control rats in the spontaneous firing of serotonergic neurons in the dorsal raphe (Maudhuit et al. 1997). After chronic exposure to unavoidable stress 5-HT output decreases in the mPFC and NAcS (Mangiavacchi et al. 2001). Some of these stress procedures have been validated as models of depression, as the behavioral and neurochemical deficit that they induce reproduces depressive symptoms (face validity), and is reverted by the administration of antidepressant compounds (predictive validity) (Willner 1997; Gambarana et al. 2001). Thus, rats subjected to the chronic mild stress (CMS) model, a chronic sequential exposure to a variety of mild stressors, show decreased drinking of a sweetened solution, a condition equated to anhedonia (Willner 1997). These rats also show a decrease of $\mathrm{D}_{2}$ DA receptor binding and mRNA levels in mesolimbic areas (Papp et al. 1994; Dziedzicka-Wasylewska et al. 1997), and a blunted phasic DA response to a feeding of palatable food in the NAcS and in the mPFC (Di Chiara and Tanda 1997). Both the behavioral and neurochemical changes induced by unavoidable stress exposure in the learned helplessness or CMS paradigms could be reversed by the chronic administration of classical antidepressant drugs (Muscat et al. 1990, 1992; Petty et al. 1992, 1994; Papp et al. 1994, 1996; Di Chiara and Tanda 1997; Dziedzicka-Wasylewska et al. 1997). Antidepressant compounds also revert the chronic escape deficit, and the drugs that we have tested in this paradigm, such as imipramine, fluoxetine, clomipramine, phenelzine, reboxetine, and a total extract of Hypericum perforatum, reinstated an avoidance response within three weeks of continuous treatment
(Gambarana et al. 1995a, 1999c, 2001; Gambarana, unpublished results). Consequently, we consider that the reversal of a behavioral deficit sustained by chronic stress is an effect that is crucial to the definition of antidepressant activity. Thus, as ALCAR administered for three weeks to chronically stressed rats did not revert the escape deficit condition, it cannot be defined an antidepressant. Indeed, in rats previously treated for 14 days with ALCAR, and that scored like naive animals when tested for escape $24 \mathrm{~h}$ after the pre-test, the exposure to chronic stress neutralized the protective effect of ALCAR. Thus, a repeated treatment with ALCAR appeared to share only some effects with imipramine, as it was able to prevent the development of the sequelae of a single, but not of a repeated, unavoidable stress. Moreover, it produced a significant increase in dopaminergic and serotonergic transmission in the NAcS, an effect that did not appear sufficient to protect rats from the disrupting sequelae of chronic stress exposure.

ALCAR has been reported to affect the cholinergic, serotonergic, dopaminergic, glutamatergic, and GABAergic systems, yet no data indicate whether these are direct or indirect effects of ALCAR (Fariello et al. 1988; Harsing et al. 1992; Tempesta et al. 1985). Moreover, the existing data on brain ALCAR distribution and on ALCAR pharmacokinetics do not add any sufficient information that could be used to clarify our results.

In conclusion, although repeated ALCAR administration consistently produced an increase in DA and 5HT output in the NAcS associated with a protective effect on acute stress exposure, on the basis of the present results, ALCAR does not seem to conform to the criteria that we use to define a compound as an antidepressant (Gambarana et al. 2001).

\section{ACKNOWLEDGMENTS}

This research was supported by a grant from the University of Siena (PAR 2000). The authors wish to thank Ms. Colleen Pisaneschi for editing the manuscript.

\section{REFERENCES}

Angelucci L, Ramacci MT (1989): Hypothalamo-pituitaryadrenocortical function in aging: effects of acetyl-L-carnitine. In De Simone C, Arrigoni-Martelli E (eds), Stress, immunity and ageing: a role for acetyl-L-carnitine. Amsterdam, Elsevier, pp 109-118

Arduini A, Gorbunov N, Arrigoni-Martelli E, Dottori S, Molajoni F, Russo F, Federici G (1993): Effects of L-carnitine and its acetate and propionate esters on the molecular dynamics of human erythrocyte membrane. Biochim Biophys Acta 1146:229-235

Aureli T, Miccheli A, Ricciolini R, Di Cocco ME, Ramacci MT, Angelucci L, Ghirardi O, Conti F (1990): Aging 
brain: Effect of acetyl-L-carnitine treatment on rat brain energy and phospholipid metabolism. A study by ${ }^{31} \mathrm{P}$ and ${ }^{1} \mathrm{H}$ NMR spectroscopy. Brain Res 526:108-112

Bell JG, Sargent JR, Tocher DR, Dick JR (2000): Red blood cell fatty acid compositions in a patient with autistic spectrum disorder: a characteristic abnormality in neurodevelopmental disorders? Prostaglandins Leukot Essent Fatty Acids 63:21-25

Bella R, Bondi R, Raffaele R, Pennisi G (1990): Effect of acetyl-L-carnitine on geriatric patients suffering from dysthymic disorders. Int J Clin Pharmacol Res 10:355360

Bidzinska B, Petraglia F, Angioni S, Genazzani AD, Criscuolo M, Ficarra G, Gallinelli A, Trentini GP, Genazzani AR (1993): Acetyl-L-carnitine effect on pituitary and plasma $\beta$-endorphin responsiveness to different chronic intermittent stressors. J Neuroendocrinol 5:151-155

Bieber LL (1988): Carnitine. Annu Rev Biochem 57:261-283

Bliss EL, Ailion J, Zwanzinger J (1968): Metabolism of norepinephrine, serotonin and dopamine in the rat brain with stress. J Pharmacol Exp Ther 164:122-134

Blokland A, Bothmer J, Honig W, Jolles J (1993): Behavioral and biochemical effects of acute central metabolic inhibition: effects of acetyl-L-carnitine. Eur J Pharmacol 235:275-281

Bresolin N, Freddo L, Vergani L, Angelini C (1982): Carnitine, carnitine acyltransferases, and rat brain function. Exp Neurol 78:285-292

Butterfield DA, Rangachari A (1993): Acetylcarnitine increases membrane cytoskeletal protein-protein interactions. Life Sci 52:297-303

Chaouloff F (2000): Serotonin, stress and corticoids. J Psychopharmacol 14:139-151

Courzon G (1971): Effects of adrenal hormones and stress on brain serotonin. Am J Clin Nutr 24:830-834

D'Amour FE, Smith DL (1941): A method for determining loss of pain sensation. J Pharmacol Exp Ther 72:74-79

De Montis MG, Gambarana C, Ghiglieri O, Tagliamonte A (1995): Reversal of stable behavioural modifications through NMDA receptor inhibition in rats. Behav Pharmacol 6:562-567

Di Chiara G, Imperato A (1988): Drugs abused by humans preferentially increase synaptic dopamine concentrations in the mesolimbic system of freely moving rats. Proc Natl Acad Sci USA 85:5274-5278

Di Chiara G, Tanda G (1997): Blunting of reactivity of dopamine transmission to palatable food: a biochemical marker of anhedonia in the CMS model? Psychopharmacology (Berl) 112:398-402

Di Chiara G, Loddo P, Tanda G (1999): Reciprocal changes in prefrontal and limbic dopamine responsiveness to aversive and rewarding stimuli after chronic mild stress: implications for the psychobiology of depression. Biol Psychiatry 46:1624-1633

Doherty MD, Gratton A (1996): Medial prefrontal cortical D1 receptor modulation of the meso-accumbens dopamine response to stress: an electrochemical study in freelybehaving rats. Brain Res 715:86-97

Dziedzicka-Wasylewska M, Willner P, Papp M (1997): Changes in dopamine receptor mRNA expression fol- lowing chronic mild stress and chronic antidepressant treatment. Behav Pharmacol 8:607-618

Fariello RG, Ferraro TN, Golden GT, Demattei M (1988): Systemic acetyl-carnitine elevates nigral levels of glutathione and GABA. Life Sci 43:289-292

Farrel S, Vogel J, Bieber LL (1986): Entry of acetyl-L-carnitine into biosynthetic pathways. Biochim Biophys Acta 876:175-177

Finlay JM, Zigmond MJ, Abercrombie ED (1995): Increased dopamine and norepinephrine release in medial prefrontal cortex induced by acute and chronic stress: effects of diazepam. Neuroscience 64:619-928

Foreman PJ, Perez-Polo JR, Angelucci L, Ramacci MT, Taglialatela G (1995): Effects of acetyl-L-carnitine treatment and stress exposure on the nerve growth factor receptor (p75NGFR) mRNA level in the central nervous system of aged rats. Prog Neuropsychopharmacol Biol 19:117-133

Forster EA, Cliffe IA, Bill DJ, Dover GM, Jones D, Reilly J, Fletcher A (1995): A pharmacological profile of the selective silent 5- $\mathrm{HT}_{1 \mathrm{~A}}$ receptor antagonist, WAY100635. Eur J Pharmacol 281:81-88

Fritz IB (1963): Carnitine and its role in fatty acid metabolism. Adv Lip Res 1:285-333

Galli G, Fratelli M (1993): Activation of apoptosis by serum deprivation in a teratocarcinoma cell line: inhibition by L-acetylcarnitine. Exp Cell Res 204:54-60

Gambarana C, Ghiglieri O, Taddei I, Tagliamonte A, De Montis MG (1995a): Imipramine and fluoxetine prevent the stress-induced escape deficits in rats through a distinct mechanism of action. Behav Pharmacol 6:66-73

Gambarana C, Ghiglieri O, Tagliamonte A, D'Alessandro N, De Montis MG (1995b): Crucial role of $D_{1}$ dopamine receptors in mediating the antidepressant effect of imipramine. Pharmacol Biochem Behav 50:147-151

Gambarana C, Masi F, Tagliamonte A, Scheggi S, Ghiglieri O, De Montis MG (1999a): A chronic stress which impairs reactivity in rats also decreases dopaminergic transmission in the nucleus accumbens: a microdialysis study. J Neurochem 72:2039-2046

Gambarana C, Ghiglieri O, Masi F, Scheggi S, Tagliamonte A De Montis MG (1999b): The effects of long-term administration of rubidium or lithium on reactivity to stress and on dopamine output in the nucleus accumbens in rats. Brain Res 826:200-209

Gambarana C, Ghiglieri O, Tolu P, De Montis MG, Giachetti D, Bombardelli E, Tagliamonte A (1999c): Efficacy of an Hypericum perforatum (St. John's wort) extract in preventing and reverting a condition of escape deficit in rats. Neuropsychopharmacol 21:247-257

Gambarana C, Scheggi S, Tagliamonte A, Tolu P, De Montis MG (2001): Animal models for the study of antidepressant activity. Brain Res Prot 7:11-20

Garzya G, Corallo D, Fiore A, Lecciso G, Petrelli G, Zotti C (1990): Evaluation of the effects of L-acetylcarnitine on senile patients suffering from depression. Drugs Exp Clin Res 16:101-106

Ghiglieri O, Gambarana C, Scheggi S, Tagliamonte A, Willner P, De Montis MG (1997): Palatable food induces an appetitive behaviour in satiated rats which can be inhibited by chronic stress. Behav Pharmacol 8:619-628 
Ghirardi O, Milano S, Ramacci MT, Angelucci R (1988): Effect of acetyl-L-carnitine chronic treatment on discrimination models in aged rats. Physiol Behav 44:769-773

Harsing LG, Sershen H, Toth E, Hashim A, Ramacci MT, Lajtha A (1992): Acetyl-L-carnitine releases dopamine in rats corpus striatum: an in vivo microdialysis study. Eur J Pharmacol 218:117-121

Hurd Y, Ungerstedt U (1989): Cocaine: an in vivo microdialysis evaluation of its acute action on dopamine transmission in rat striatum. Synapse 3:48-54

Kalivas PW, Duffy P (1995): Selective activation of dopamine transmission in the shell of the nucleus accumbens by stress. Brain Res 675:325-328

Kaneyuki H, Yokoo H, Tsuda A, Yoshida M, Mizuki Y, Yamada M, Tanaka M (1991): Psychological stress increases dopamine turnover selectively in mesoprefrontal dopamine neurons in rats: reversal by diazepam. Brain Res 557:154-161

Kirkby DL, Jones DN, Barnes JC, Higgins GA (1996): Effects of anticholinesterase drugs tacrine and E2020, the 5- $\mathrm{HT}_{3}$ antagonist ondansentron, and the $\mathrm{H}_{3}$ antagonist thioperamide, in models of cognition and cholinergic function. Behav Pharmacol 7:513-525

Konstandi M, Johnson E, Lang MA, Malamas M, Marselos M (2000): Noradrenaline, dopamine, serotonin: different effects of psychological stress on brain biogenic amines in mice and rats. Pharmacol Res 41:341-346

Kuratsune H, Watanabe Y, Yamaguti K, Jacobsson G, Takahashi M, Machii T, Onoe H, Onoe K, Matsumura K, Valind S, Kitani T, Längström B (1997): High uptake of [2${ }^{11}$ C]acetyl-L-carnitine into the brain: a PET study. Biochem Biophys Res Commun 231:488-493

Liu Y, Rosenthal RE, Stark-Reed P, Fiskum G (1993): Inhibition of postcardiac arrest brain protein oxidation by acetyl-L-carnitine. Free Radic Biol Med 15:667-670

Mangiavacchi S, Masi F, Scheggi S, Leggio B, De Montis MG, Gambarana C (2001): Long-term behavioral and neurochemical effects of chronic stress exposure in rats. J Neurochem 78:1-10

Maudhuit C, Prevot E, Dangoumau L, Martin P, Hamon M, Adrien J (1997): Antidepressant treatment in helpless rats: effect on the electrophysiological activity of raphe dorsalis serotonergic neurons. Psychopharmacology (Berl) 130:269-275

Meloni D, Gambarana C, De Montis MG, Dal Prá P, Taddei I, Tagliamonte A (1993): Dizocilpine antagonizes the effect of chronic imipramine on learned helplessness in rats. Pharmacol Biochem Behav 46:423-426

Moreau JL, Jenck F, Martin JR, Mortas P, Haefely WE (1992): Antidepressant treatment prevents chronic unpredictable mild stress-induced anhedonia as assessed by ventral tegmentum self-stimulation behavior in rats. Eur Neuropsychopharmacol 2:43-49

Muscat R, Sampson D, Willner P (1990): Dopaminergic mechanism of imipramine action in an animal model of depression. Biol Psychiatry 28:223-230

Muscat R, Papp M, Willner P (1992): Reversal of stressinduced anhedonia by the atypical antidepressants, fluoxetine and maprotiline. Psychopharmacology (Berl) 109:433-438

Overmier JB, Seligman MEP (1967): Effects of inescapable shock upon subsequent escape and avoidance learning. J Comp Physiol Psychol 63:23-33

Pani L, Porcella A, Gessa GL (2000): The role of stress in the pathophysiology of the dopaminergic system. Mol Psychiatry 5:14-21

Papp M, Willner P, Muscat R (1991): An animal model of anhedonia: attenuation of sucrose consumption and place preference conditioning by chronic unpredictable mild stress. Psychopharmacology (Berl) 104: 255-259

Papp M, Klimek V, Willner P (1994): Parallel changes in dopamine $\mathrm{D}_{2}$ receptor binding in limbic forebrain associated with chronic mild stress-induced anhedonia and its reversal by imipramine. Psychopharmacology (Berl) 115:441-446

Papp M, Moryl E, Willner P (1996): Pharmacological validation of the chronic mild stress model of depression. Eur J Pharmacol 296:129-136

Parnetti L, Gaiti A, Mecocci P, Cadini D, Senin U (1997): Pharmacokinetics of IV and oral acetyl-L-carnitine in a multiple dose regimen in patients with senile dementia of Alzheimer type. Eur J Clin Pharmacol 42:89-93

Pascale A, Milano S, Corsico N, Lucchi L, Battaini F, Arrigoni Martelli E, Trabucchi M, Govoni S (1994): Protein kinase $\mathrm{C}$ activation and anti-amnesic effect of acetyl-L-carnitine: in vitro and in vivo studies. Eur J Pharmacol 265:1-7

Patacchioli FR, Amenta R, Ramacci MT, Taglialatela G, Maccari S, Angelucci L (1989): Acetyl-L-carnitine reduces the age-dependent loss of glucocorticoid receptors in the rat hippocampus: an autoradiographic study. J Neurosci Res 23:462-466

Paxinos G, Watson C (1986): The rat brain in stereotaxic coordinates. New York, Academic Press

Pettegrew J, Klunk W, Panchalingam K, Kanfer JN, McClure RJ (1995): Clinical and neurochemical effects of acetyl-Lcarnitine in Alzheimer's disease. Neurobiol Aging 16:1-4

Pettegrew JW, Levine J, McClure RJ (2000): Acetyl-L-carnitine physical-chemical, metabolic, and therapeutic properties: relevance for its mode of action in Alzheimer's disease and geriatric depression. Mol Psychiatry 5:616-632

Petty F, Kramer G, Wilson L (1992): Prevention of learned helplessness: in vivo correlation with cortical serotonin. Pharmacol Biochem Behav 43:361-367

Petty F, Kramer G, Wilson L, Jordan S (1994): In vivo serotonin release and learned helplessness. Psychiatry Res 52:285-293

Prickaerts J, Blokland A, Honig W, Meng F, Jolles J (1995): Spatial discrimination learning and choline acetyltransferase activity in streptozocin-treated rats: effects of chronic treatment with acetyl-L-carnitine. Brain Res 674:142-146

Rao KV, Mawal YR, Qureshi IA (1997): Progressive decrease of cerebral cytochrome $C$ oxidase activity in sparse-fur mice: role of acetyl-L-carnitine in restoring the ammonia-induced cerebral energy depletion. Neurosci Lett 224:83-86

Richardson AJ, Ross MA (2000): Fatty acid metabolism in neurodevelopmental disorder: a new perspective on associations between attention-deficit/hyperactivity disorder, dyslexia, dyspraxia and the autistic spectrum. Prostaglandins Leukot Essent Fatty Acids 63:1-9 
Richardson AJ, Puri BK (2000): The potential role of fatty acids in attention-deficit/hyperactivity disorder. Prostaglandins Leukot Essent Fatty Acids 63:79-87

Rosenthal RE, Williams R, Bogaert YE, Getson PR, Fiskum G (1992): Prevention of postischemic canine neurological injury through potentiation of brain energy metabolism by acetyl-L-carnitine. Stroke 23:1312-1318

Rouge-Pont F, Piazza PV, Kharouby M, Le Moal M, Simon H (1993): Higher and longer stress-induced increase in dopamine concentrations in the nucleus accumbens of animals predisposed to amphetamine self-administration. A microdialysis study. Brain Res 602:169-174

Sorg BA, Kalivas PW (1993): Effects of cocaine and footshock stress on extracellular dopamine levels in the medial prefrontal cortex. Neuroscience 53:695-703

Tempesta E, Janiri L, Pirrongelli C (1985): Stereospecific effects of acetylcarnitine on the spontaneous activity of brainstem neurones and their response to acetylcholine and serotonin. Neuropharmacology 24:43-50

Tidey JW, Miczek KA (1996): Social defeat stress selectively alters mesocorticolimbic dopamine release: an in vivo microdialysis study. Brain Res 721:140-149

Villa RF, Turpeenoja L, Benzi G, Giuffrida SM (1988): Action of L-acetylcarnitine on age-dependent modifications of mitochondrial membrane proteins from rat cerebellum. Neurochem Res 13:909-916

Willner P (1997): Validity, reliability and utility of the chronic mild stress model of depression: a 10-year review and evaluation. Psychopharmacology (Berl) 134:319-329

Yoshioka M, Matsumoto M, Togashi H, Saito H (1996): Effect of conditioned fear stress on dopamine release in the rat prefrontal cortex. Neurosci Let 209:201-203 